\title{
ArcheoSciences
}

Revue d'archéométrie

33 (suppl.) | 2009

Mémoire du sol, espace des hommes

\section{Ground penetrating radar surveys of Viejo Period settlements of the Chihuahua Culture, Upper Santa Maria Valley, Chihuahua, Mexico}

Jean-Michel Maillol, Richard D. Garvin, Jane H. Kelley and Dominic Lacroix

\section{OpenEdition}

Journals

Electronic version

URL: https://journals.openedition.org/archeosciences/1371

DOI: 10.4000/archeosciences. 1371

ISBN: 978-2-7535-1599-4

ISSN: 2104-3728

Publisher

Presses universitaires de Rennes

\section{Printed version}

Date of publication: 30 October 2009

Number of pages: 105-107

ISBN: 978-2-7535-0943-6

ISSN: 1960-1360

\section{Electronic reference}

Jean-Michel Maillol, Richard D. Garvin, Jane H. Kelley and Dominic Lacroix, "Ground penetrating radar surveys of Viejo Period settlements of the Chihuahua Culture, Upper Santa Maria Valley, Chihuahua, Mexico", ArcheoSciences [Online], 33 (suppl.) | 2009, Online since 30 October 2011, connection on 01 February 2022. URL: http://journals.openedition.org/archeosciences/1371 ; DOI: https://doi.org/ 10.4000/archeosciences.1371 


\title{
Ground penetrating radar surveys of Viejo Period settlements of the Chihuahua Culture, Upper Santa Maria Valley, Chihuahua, Mexico
}

\author{
Jean-Michel MaIllol ${ }^{*}$, Richard D. Garvin ${ }^{* *}$, \\ Jane H. KelleY ${ }^{* * *}$ and Dominic LaCroiX ${ }^{* * *}$
}

Key words: Ground penetrating radar, Chihuahua culture, Settlement, Viejo period, Mexico

\section{ArChaEological BACKGround}

The first major project pertaining to the Chihuahua Culture was conducted by Charles Di Peso and colleagues during the late 1950's and early 1960's (Di Peso, 1974). Their work was primarily concerned with the site of Paquimé (Casas Grandes), now a World Heritage site and the most renowned Mexican archaeological site north of Mesoamerica proper. Di Peso defined the Viejo, Medio and Tardio periods primarily on the basis of a few sites located in close proximity to each other. In 1989, interest in Chihuahua revived after Mexican archaeologists were assigned to the Chihuahua Regional Office of the Instituto Nacional de Anthropología e Historia (INAH), and three long-term projects were initiated. One of these was the Proyecto Arqueológico Chihuahua (PAC) with Jane Kelley and Joe Stewart as co-directors (Stewart et al, 2005). This was the only project to move into the upland part of the Chihuahua Culture area away from the lowland desert where the largest and best-known sites are located (Fig.1). Five Viejo period (ca. A.D. 7001200) sites were located, and excavations were undertaken at three of them. The findings suggested that Viejo period

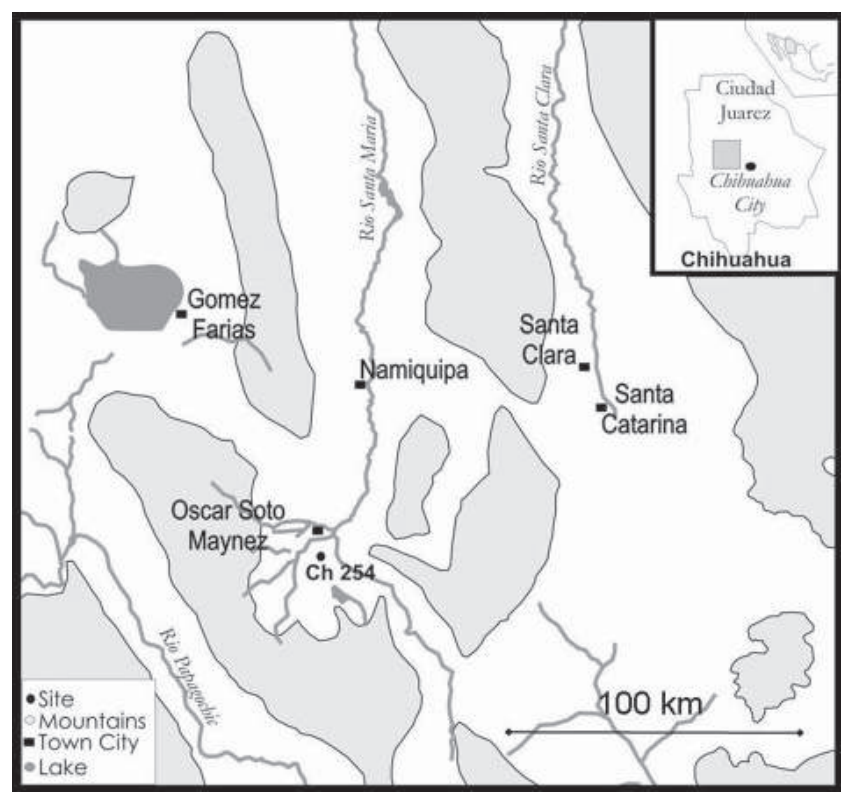

Figure 1: Map of the project area with location of site $\mathrm{CH}-254$ discussed in this paper.

*ArchaeoVision Consulting, 501 - 91816 AVE NW, Calgary, Alberta, Canada, T2M 0K3. (maillol@archaeovision.com)

** Community, Culture and Global Studies, University of British Columbia Okanagan, 3333 University Way, Kelowna, BC V1V 1 V7.

*** Department of Archaeology, University of Calgary, 2500 University Drive NW, Calgary, Alberta, Canada, T2N 1N4. 
populations must have been substantially larger than was previously believed, and that the basic characteristics that became the hallmarks of the Medio period were in place in the Viejo period.

The next important step in Viejo period research is to gain improved knowledge about whole settlements and their populations. In order to look at the larger picture, we need to know the size of communities in terms of numbers of structures and their placements, their temporal relationships, and whether there are specialized structures. To address these issues a new project was started in 2005. One of its main aspects is to use ground penetrating radar (GPR) to map and delineate entire sites and to more accurately locate archaeological features at Viejo period sites where structures have little or no surface expression. Sub-surface targets are buried under a relatively thin overburden consisting mostly of dry agricultural soil and alluvial sediments. From the experience of earlier projects, the maximum depth of cultural deposits is not expected to exceed 1 to $1.5 \mathrm{~m}$. Archaeological signals are expected to originate mainly from packed clay floors, collapsed building materials, post-holes and occupation surfaces.

\section{SURVEY PROCEDURES AND RESULTS}

To date seven sites have been surveyed, ranging from 2,500 to 15,000 square metres. A Sensors \& Software Noggin ${ }^{\oplus} 500 \mathrm{MHz}$ system was used for all surveys. For all sites, a survey strategy based upon 50x $25 \mathrm{~m}$ sub-grids consisting of N-S profiles spaced $0.5 \mathrm{~m}$ apart was used. Along these profiles GPR traces were recorded at $2.5 \mathrm{~cm}$ intervals. The individual profiles were processed following a standard common-offset flow including: time-zero correction, dewow filter, spherical and exponential amplitude compensation, band-pass filter, and background removal. Additionally, an $\mathrm{f}-\mathrm{k}$ migration using a constant velocity was performed. At all the sites velocities were determined by analysis of point reflection hyperbolas at various locations and depths. In addition, for two of the most productive sites direct velocity measurements were performed by placing a length of rebar at various known depths in the wall of test excavations. These experiments revealed low intra-site velocity variability. Consequently, a constant average velocity was used for migration and depth conversion of the GPR profiles. The pseudo-3D data sets were used to produce data volumes and time slices. While structures and other suspected archaeological targets were identified at six of the seven sites, this paper describes results from only one site referenced as $\mathrm{Ch}$ 254 (Fig. 1).

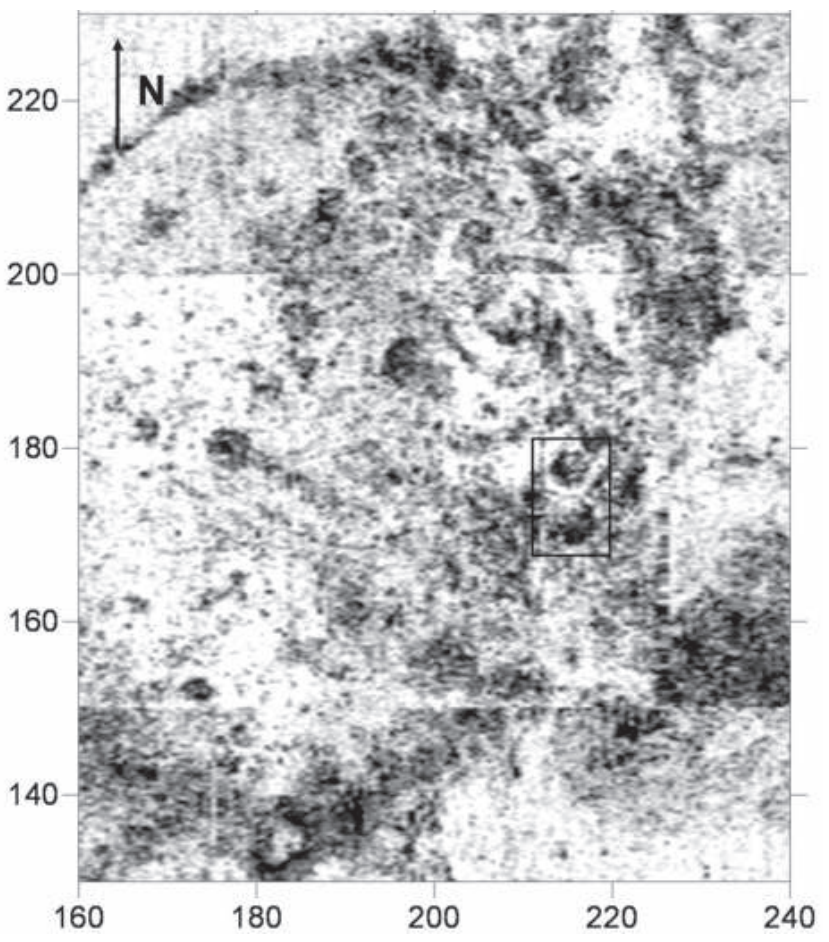

Figure 2: GPR time slice obtained at $\mathrm{CH} 254$. Travel time is 11 ns and the slide "thickness" is 1 ns. Dark shades correspond to high reflectivity. A number of high reflectivity anomalies of full or partial circular shape are visible and interpreted as semi-subterranean dwellings ("pithouses"). The rectangular box indicates the area subjected to detailed excavation testing (see also Fig.3). Distance scale is in metre.

$\mathrm{CH}-254$, the Calderon Site, is located on a tributary entering the Santa Maria Valley from the southwest (Fig. 1). A minimum of 22 circular reflective anomalies were identified on time slices at different depths and interpreted as pithouses. Figure 2 shows an example of such a time slice. Numerous other reflecting areas are present, but their lack of regular shape makes it impossible to attribute them with certainty to archaeological targets without direct testing. To verify the interpretation of the circular patterns, two closely spaced anomalies were selected for trench testing in 2005. Two walls corresponding to two apparently distinct dwellings were discovered at the exact locations of the circular reflections visible on the GPR time slices (Fig $3 a$ and $3 b$ ). The results were so encouraging that the northern structure was selected for full-fledge excavating in 2007-2008 (Fig. 3c). The excavation revealed a complete partly subterranean house with several superposed floors. The dimensions of the house match closely what could be inferred from the GPR data. The first floor appears at $0.25 \mathrm{~m}$ depth while the first reflection on the GPR data appears at approxima- 


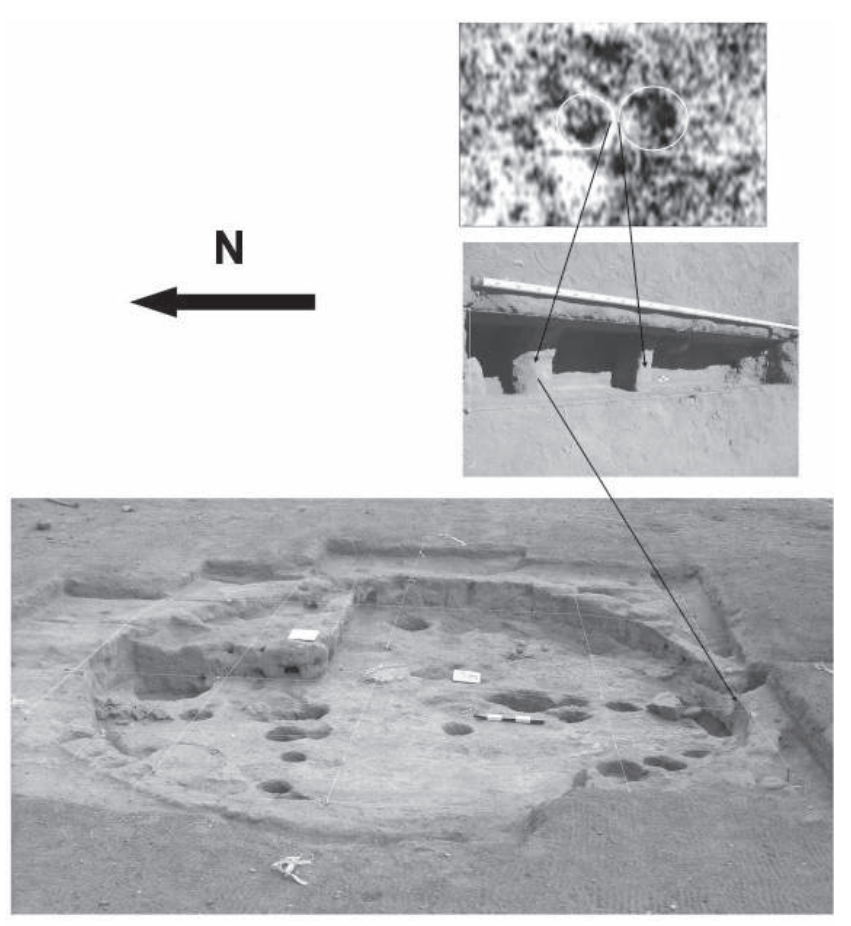

Figure 3: (a) detail of time slice showing two adjacent circular reflectivity anomalies; (b) test trench dug in 2005 showing two house walls; (c) fully excavated house in 2008.

tely $40 \mathrm{~cm}$. This difference may be due to an overestimated propagation velocity, to the inability to record very shallow reflections or to the fact that the bottom of the structure offers the strongest reflectivity contrast.

\section{Conclusions}

The use of GPR in this region does appear to allow for the mapping of sub-surface archaeological features, both horizontally and vertically. Subsurface mapping of entire Viejo period settlements is therefore a definite possibility. Higher resolution surveys on limited area of the study sites, not discussed in this overview paper, have shown that smaller, specific features, such as house posts, are identifiable within suspected pithouses. These details added to accurate estimates of the dimensions of structures before excavation are an invaluable help in the planning and execution of major excavation projects.

The refinement and systematic use of GPR surveys in the region will allow for more efficient use of archaeological field time and research funds. By defining the size of pithouses, along with their horizontal and vertical distributions, questions pertaining to land use and social organization may be acquired with fewer large-scale, time consuming excavations. The advantage here lies not only in a more efficient use of research funding, but also in the protection of the prehistoric cultural resources themselves as excavation identifies the location of sites which may, and often does, lead to looting.

\section{References}

Di Peso, C., 1974. Casas Grandes: A fallen trading center of the Gran Chichimeca (Vols. 1-3). The Amerind Fondation and Northland Press, Flagstaff.

Stewart, J. D., Kelley, J. H., MacWilliams, A. C. and Reimer, P., 2005. The Viejo Period Culture in Northwestern Mexico: Recent excavations and radiocarbon dating. Latin American Antiquity 16(2): 169-192. 